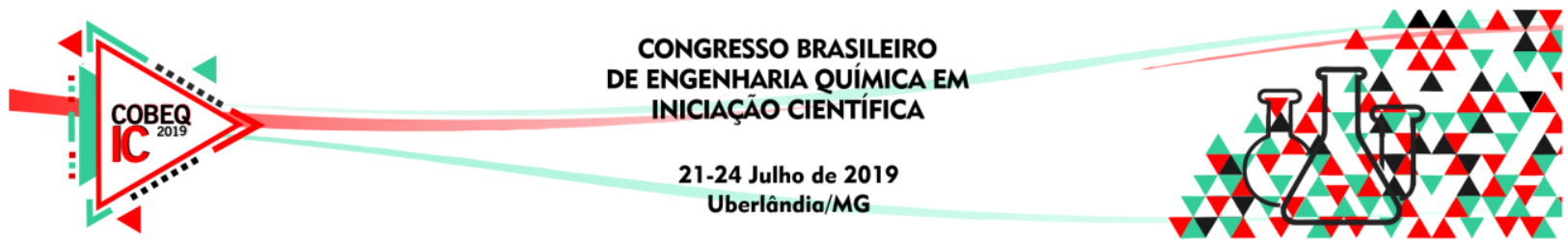

\title{
COMPARAÇÃO DA QUANTIFICAÇÃO DE ESCHERICHIA COLI ENTRE BALNEÁRIOS RURAIS EM RELAÇÃO AO ÍNDICE PLUVIOMÉTRICO
}

\author{
Y. G. PEDDE ${ }^{1}$ e C. A. NASCIMENTO ${ }^{2}$ \\ ${ }^{1}$ Universidade Feevale, Graduando de Engenharia Química e Bolsista FAPERGS \\ ${ }^{2}$ Universidade Feevale, Instituto de Ciências Exatas e Tecnológicas (ICET) \\ E-mail para contato: yuriprofissional16@gmail.com, nascimento@feevale.br
}

\begin{abstract}
RESUMO - Embora a água dos chamados balneários rurais da Bacia Hidrográfica dos Sinos seja, pelo senso comum, considerada "limpa", fez-se necessária a avaliação da mesma quanto a balneabilidade, já que em períodos de alta temperatura existe grande circulação de pessoas. Feita a análise, confirmou-se que, de acordo com a Resolução do Conselho Nacional do Meio Ambiente n274/2000, essas águas eram impróprias quanto ao parâmetro, pois apresentavam um NMP/100mL de E. coli superior ao permitido em diversas amostras. De acordo com a literatura e com a quantificação da precipitação acumulada nos períodos quando foram realizadas as coletas, identificou-se uma correlação entre a pluviosidade, registrada horas antes da coleta ou em um período de tempo maior antes da mesma, com a concentração de E. coli.
\end{abstract}

\section{INTRODUÇÃO}

A Bacia Hidrográfica dos Sinos, no nordeste do Rio Grande do Sul, possui, por sua extensão, locais comumente utilizados para banho e consequente contato primário entre ser humano e água. Esses lugares afastados da área urbana tornam-se, a medida de sua popularização, os chamados "balneários rurais". A maioria desses, entretanto, não possuem fiscalização quanto à balneabilidade, embora exista grande circulação de pessoas em períodos quentes.

A padronização da qualidade da água relativa à balneabilidade é estabelecida pela Resolução CONAMA n- 274/2000, a qual classifica essa água em própria e imprópria para banho. Essa predita, entre outros parâmetros de avaliação, o NMP de E.coli por 100mL. Ela prevê, neste caso, coleta da água em questão durante cinco semanas. Para estar de acordo com o padrão, $80 \%$ das amostras precisam mostrar-se abaixo de $800 \mathrm{NMP} / 100 \mathrm{~mL}$ e a última deve ser inferior à $2000 \mathrm{NMP} / 100 \mathrm{~mL}$. As coletas foram feitas em três pontos: Cascata das Andorinhas (ponto 1), em Rolante, Balneário Conduto (ponto 2), Riozinho e Cascata dos Italianos (ponto 3), Taquara, três balneários rurais da região.

\subsection{Relação entre chuva, qualidade da água e quantidade de $E$. coli}




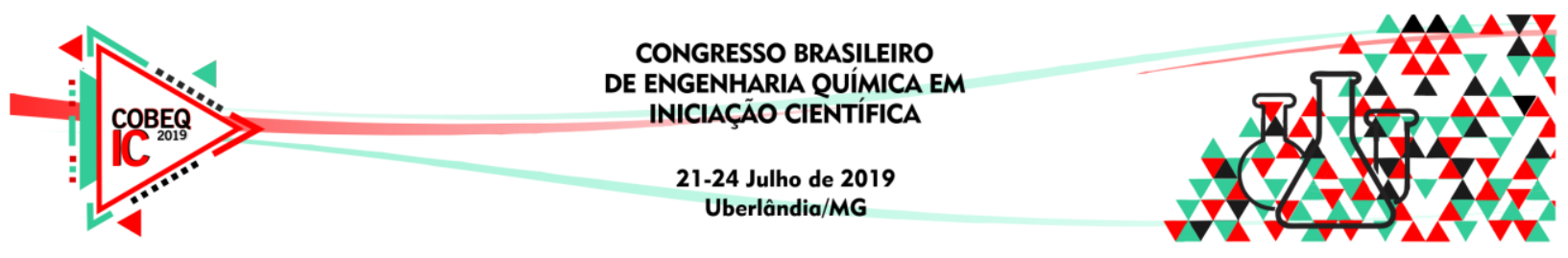

Existem diversos trabalhos na literatura que ligam, de forma qualitativa e quantitativa, a qualidade microbiológica da água com o regime de chuvas. A concentração de E. coli é um dos indicadores de qualidade microbiológica dos meios aquáticos que é relacionada tanto à sazonalidade e as consequentes chuvas dos períodos, quanto à pluviosidade em um curto espaço de tempo e sua influência imediata no parâmetro. Portanto, o monitoramento da água de locais como os balneários rurais deve ser periódico, tendo em vista que a contaminação é um processo dinâmico.

Não são somente, entretanto, as águas de balneários rurais que são afetadas em sua qualidade química, física e microbiológica pela pluviosidade, mas também a água do mar e água subterrânea, como poços rasos, e nascentes.

O estudo de Valias et al. (2002) a respeito da análise microbiológica da água de nascentes e poços rasos de propriedades rurais conclui que, com o aumento da precipitação durante períodos do ano, aumentam também os índices de contaminação, pois mais propriedades rurais, dentre as analisadas, apresentaram-se fora dos padrões estabelecidos nas épocas de chuvas.

Sholten (2009) também ressalta a relação direta entre a alta pluviosidade de um período com a contaminação microbiológica de águas superficiais, nesse caso de mananciais. De acordo com a autora, verifica-se a maior média de coliformes no período chuvoso, fato que é causado pela grande vazão de esgoto, poluentes agropecuários e, principalmente, detritos de animais, como esterco líquido e estrume.

Para uma análise mais precisa da relação entre a precipitação $(\mathrm{mm})$ e a concentração de E. Coli, é necessária uma avaliação da consequência da chuva em um espaço de tempo curto. Para isso, Kleinheinz et al. (2009) coletou amostras das águas de praias localizadas em Door County, Wisconsin (EUA), durante chuvas que acumularam, no mínimo, 5mm, nas 24 horas anteriores. Determinou-se assim, que a maioria das amostras mostrou elevada relação entre grande concentração de E.coli e chuvas de $5 \mathrm{~mm}$ ou mais nesse período curto de tempo.

\section{OBJETIVOS}

Comparar a quantificação de E. Coli em três balneários rurais da Bacia Hidrográfica dos Sinos durante o período de alta temperatura do ano de 2018 com o de 2019 e o de baixa temperatura de 2018. Relacionar, ainda, os resultados com o índice pluviométrico do período de 60 dias, 31 deles anteriores à coleta e 29 no período da bateria de coletas, além de relacionar o índice pluviométrico das 24 horas que antecederam a retirada de cada amostra, explorando, assim, as causas a curto e longo prazo para tais quantificações.

\section{MATERIAIS E MÉTODOS}

Foram coletadas cinco amostras de cada ponto, durante cinco semanas consecutivas em cada bateria de coletas, que foram três ao total. Na primeira bateria, no período quente de 2018, as amostras foram recolhidas do dia 26 de fevereiro ao dia 26 de março, enquanto que na segunda bateria, no inverno de 2018, foram recolhidas do dia 12 de julho ao dia 9 de agosto. Já a terceira bateria foi realizada no verão de 2019, do dia 9 de janeiro ao dia 6 de fevereiro. 
Todos os dados de pluviosidade foram adquiridos a partir do site de uma estação da rede de monitoramento Weather Underground.

As amostras foram analisadas quanto à presença de Escherichia coli, com o kit Colilert para detecção de atividade da enzima $\beta$-glucurinodase, que utiliza o substrato MUG.

\section{RESULTADOS}

As Tabelas 1, 2 e 3 indicam o NMP/100mL da bactéria nos três pontos de coleta, sendo elas respectivamente da primeira, segunda e terceira baterias de coleta.

Tabela 1 - NMP/100mL de E. coli nos três pontos na primeira bateria de coletas

\begin{tabular}{|c|c|c|c|}
\hline \multirow{2}{*}{ Data } & \multicolumn{3}{|c|}{ NMP de E. coli $/ 100 \mathrm{~mL}$} \\
\cline { 2 - 4 } & P1 & P2 & P3 \\
\hline \hline $26 / 02 / 2018$ & 200 & 140 & 63 \\
\hline $05 / 03 / 2018$ & $\mathbf{1 6 0 0 0}$ & 290 & 200 \\
\hline $12 / 03 / 2018$ & 790 & 700 & 210 \\
\hline $19 / 03 / 2018$ & 220 & $\mathbf{1 4 0 0}$ & 190 \\
\hline $26 / 03 / 2018$ & $\mathbf{4 1 0 0}$ & $\mathbf{3 3 0 0}$ & $\mathbf{4 1 0 0}$ \\
\hline
\end{tabular}

Tabela 2 - NMP/100mL de E. coli nos três pontos na segunda bateria de coletas

\begin{tabular}{|c|c|c|c|}
\hline \multirow{2}{*}{ Data } & \multicolumn{3}{|c|}{ NMP de E. coli $/ 100 \mathrm{~mL}$} \\
\cline { 2 - 4 } & $\mathrm{P} 1$ & $\mathrm{P} 2$ & $\mathrm{P3}$ \\
\hline \hline $12 / 07 / 2018$ & 200 & $\mathbf{3 0 5 0}$ & $\mathbf{8 5 0}$ \\
\hline $19 / 07 / 2018$ & 200 & 310 & 520 \\
\hline $26 / 07 / 2018$ & 410 & 630 & $\mathbf{2 2 0 0}$ \\
\hline $02 / 08 / 2018$ & $<\mathrm{LQ}^{*}$ & 100 & 200 \\
\hline $09 / 08 / 2018$ & $\mathbf{2 3 1 0}$ & $\mathbf{1 8 7 0}$ & $\mathbf{8 5 0}$ \\
\hline \multirow{2}{*}{$*<\mathrm{LQ}=<$ Limite de quantificação, que é 1.}
\end{tabular}

Tabela 3 - NMP/100mL de E. coli nos três pontos na terceira bateria de coletas

\begin{tabular}{|r|r|r|r|}
\hline \multirow{2}{*}{ Data } & \multicolumn{3}{|c|}{ NMP de E. coli / 100mL } \\
\cline { 2 - 4 } & P1 & P2 & P3 \\
\hline \hline $09 / 01 / 2019$ & 200 & 580 & 610 \\
\hline $16 / 01 / 2019$ & $\mathbf{2 4 0 0}$ & $\mathbf{2 4 0 0 0}$ & $\mathbf{2 0 0 0 0}$ \\
\hline $23 / 01 / 2019$ & 150 & 290 & $\mathbf{1 1 0 0}$ \\
\hline $30 / 01 / 2019$ & 340 & 160 & $\mathbf{2 9 0 0}$ \\
\hline $06 / 02 / 2019$ & $\mathbf{1 2 0 0}$ & 86 & 370 \\
\hline
\end{tabular}




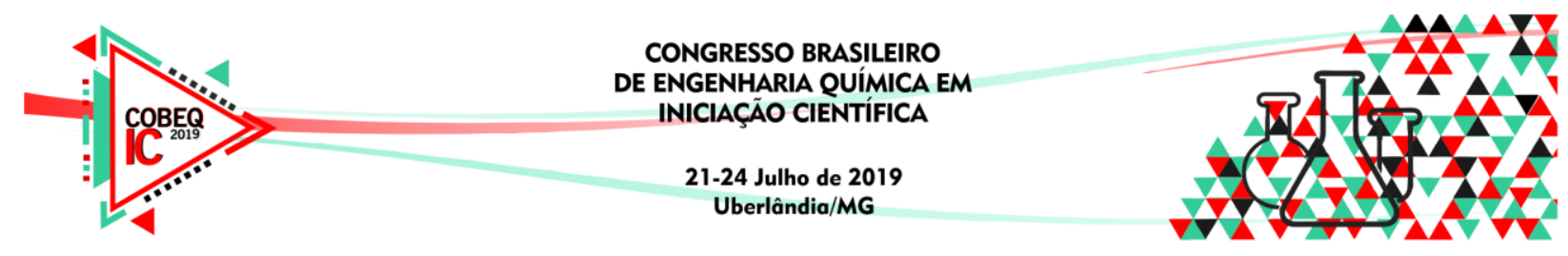

De acordo com os resultados e com o padrão estabelecido pela resolução CONAMA n274/2000, torna-se claro que, na primeira bateria, todos os pontos mostram-se impróprios para banho, já que todos possuem mais que $2000 \mathrm{NMP} / 100 \mathrm{~mL}$ na última amostra. A tabela 2, por sua vez, também demonstra que os três pontos mostraram-se impróprios quanto à balneabilidade. Nessa bateria, entretanto, dois pontos (ponto 2 e ponto 3) dispuseram dessa classificação por possuírem menos que $80 \%$ das amostras inferiores a $800 \mathrm{NMP} / 100 \mathrm{~mL}$. A tabela 3 relata, entretanto, a impropriedade somente dos pontos 1 e 3 , por possuírem $40 \%$ e $60 \%$ das amostras superiores a $800 \mathrm{NMP} / 100 \mathrm{~mL}$, respectivamente, enquanto o ponto 2 mostrou-se próprio para banho.

A Tabela 4 indica a pluviosidade na região de Taquara nos 31 dias anteriores ao início da bateria de coletas somados com os 29 dias das cinco semanas consecutivas de coleta, justamente para colocar em perspectiva a influência de um período de mais ou menos pluviosidade.

Tabela 4 - Pluviosidade de 60 dias, 31 antes da coleta e 29 durante as coletas, nas 3 baterias

\begin{tabular}{|c|c|c|c|c|c|}
\hline \multicolumn{2}{|c|}{ Bateria 1 } & \multicolumn{2}{c|}{ Bateria 2 } & \multicolumn{2}{c|}{ Bateria 3 } \\
\hline Data & $\begin{array}{c}\text { Pluviosidade nos } \\
60 \text { dias }\end{array}$ & Data & $\begin{array}{c}\text { Pluviosidade nos } \\
60 \text { dias }\end{array}$ & Data & $\begin{array}{c}\text { Pluviosidade nos } \\
60 \text { dias }\end{array}$ \\
\hline $\begin{array}{c}25 / 01 \text { até } \\
26 / 03 / 2018\end{array}$ & $117,6 \mathrm{~mm}$ & $\begin{array}{c}11 / 06 \text { até } \\
9 / 08 / 2018\end{array}$ & $264,4 \mathrm{~mm}$ & $\begin{array}{c}9 / 12 \text { até } \\
6 / 2 / 2019\end{array}$ & $212,6 \mathrm{~mm}$ \\
\hline
\end{tabular}

A Tabela 2 indica que seis (6) amostras apresentaram-se como superiores a 800 NMP/100mL, quando o índice pluviométrico dos 60 dias analisados foi de 264,4 mm, de acordo com a Tabela 4. A Tabela 3 indica que também seis (6) amostras, naquele período, foram superiores ao limite padronizado, enquanto o índice pluviométrico foi de $212,6 \mathrm{~mm}$, como representa a Tabela 4. Já na primeira bateria de coletas, com 117,6 mm de chuva, cerca de metade do índice pluviométrico em relação ao período das outras duas baterias de coletas, 5 amostras mostraram-se superiores ao limite estabelecido. Portanto, como indica a literatura, é provável que tenha existido correlação entre o índice de chuvas sazonais com a quantificação de E.Coli e consequente qualidade da água dos balneários rurais onde as amostras foram coletadas.

As tabelas 5, 6 e 7 indicam a pluviosidade nas 24 horas que antecederam cada coleta até o momento de recolhimento da amostra. As 24 horas foram utilizadas considerando-se que as amostras do Ponto 1 foram coletas sempre às $11 \mathrm{~h}$, as do ponto 2 , às $10 \mathrm{~h}$ e as do ponto 3 , às $13 \mathrm{~h}$. 
Tabela 5 - Pluviosidade $24 \mathrm{~h}$ antes de cada coleta na primeira bateria

\begin{tabular}{|c|c|c|c|}
\hline \multicolumn{4}{|c|}{ Bateria 1} \\
\hline \multirow[t]{2}{*}{ Data } & \multicolumn{3}{|c|}{$\begin{array}{c}\text { Índice de chuva } \\
24 \mathrm{~h} \text { antes até o } \\
\text { momento da } \\
\text { coleta }(\mathrm{mm})\end{array}$} \\
\hline & P1 & P2 & P3 \\
\hline $26 / 02 / 2018$ & SD** & SD & SD \\
\hline $05 / 03 / 2018$ & 0 & 0 & 0 \\
\hline $12 / 03 / 2018$ & 3 & 3 & 3 \\
\hline $19 / 03 / 2018$ & 12,2 & 12,2 & 12,2 \\
\hline $26 / 03 / 2018$ & 4,8 & 4,5 & 4,8 \\
\hline
\end{tabular}

Tabela 6 - Pluviosidade 24h antes de cada coleta na segunda bateria

\begin{tabular}{|c|c|c|c|}
\hline \multirow{4}{*}{ Bata } & \multicolumn{3}{|c|}{$\begin{array}{c}\text { Índice de chuva } \\
24 \mathrm{~h} \text { antes até o } \\
\text { momento da } \\
\text { coleta (mm) }\end{array}$} \\
\cline { 2 - 4 } & P1 & P2 & P3 \\
\hline \hline $12 / 07 / 2018$ & 0 & 0 & 0 \\
\hline $19 / 07 / 2018$ & 0,3 & 0,3 & 0,3 \\
\hline $26 / 07 / 2018$ & 8,9 & 6,4 & 5,4 \\
\hline $02 / 08 / 2018$ & 0 & 0 & 0 \\
\hline $09 / 08 / 2018$ & 14,5 & 14,5 & 14,5 \\
\hline
\end{tabular}

Tabela 7 - Pluviosidade $24 \mathrm{~h}$ antes de cada coleta na terceira bateria

\begin{tabular}{|c|c|c|c|}
\hline \multirow{4}{*}{ Bata } & \multicolumn{3}{|c|}{$\begin{array}{c}\text { Índice de chuva } \\
24 \mathrm{~h} \text { antes até o } \\
\text { momento da } \\
\text { coleta (mm) }\end{array}$} \\
\cline { 2 - 4 } & $\mathrm{P} 1$ & $\mathrm{P} 2$ & $\mathrm{P3}$ \\
\hline \hline $09 / 01 / 2019$ & 2,8 & 2,8 & 2,8 \\
\hline $16 / 01 / 2019$ & 14,7 & 14,7 & 14,7 \\
\hline $23 / 01 / 2019$ & 0 & 0 & 0 \\
\hline $30 / 01 / 2019$ & 0,5 & 0,5 & 0,5 \\
\hline $06 / 02 / 2019$ & 0 & 0 & 0 \\
\hline
\end{tabular}

Relacionando as tabelas 5, 6 e 7 com as tabelas 1,2 e 3 percebe-se que, no ponto 1 , $50 \%$ das vezes que ocorreu uma pluviosidade superior a $5 \mathrm{~mm}$ nas últimas $24 \mathrm{~h}$ a amostra 


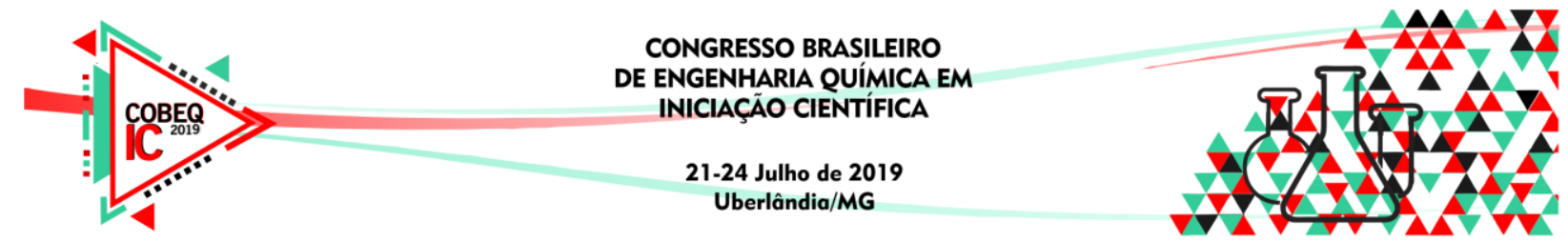

ultrapassou o limite estabelecido de $800 \mathrm{NMP} / 100 \mathrm{~mL}$, enquanto que $70 \%$ das amostras coletadas num período de $24 \mathrm{~h}$ com menos de $5 \mathrm{~mm}$ de chuva mostraram-se inferiores ao limite.

No ponto $2,75 \%$ das vezes nas quais ocorreu uma pluviosidade superior a $5 \mathrm{~mm}$ a amostra ultrapassou o limite, bem como $80 \%$ das amostras do período no qual choveu menos que $5 \mathrm{~mm}$ ficaram dentro do parâmetro estipulado.

No ponto $3,75 \%$ das amostras as quais representam uma pluviosidade superior a $5 \mathrm{~mm}$ ultrapassaram o limite, enquanto $60 \%$ das amostras as quais representam uma pluviosidade inferior a $5 \mathrm{~mm}$ não ultrapassaram o limite.

Portanto, como demonstra Kleinheinz (2009), existe sim uma correlação entre a pluviosidade no período de $24 \mathrm{~h}$ que antecedem a coleta sobre a concentração E. coli. Essa correlação foi, de acordo com este trabalho, mais linear do que a correlação entre as tabelas 1 , 2,3 e 4 . Isso é esperado, já que uma análise mais específica torna a avaliação mais clara e concreta do que uma análise geral de 60 dias, quando não se pode definir em que momento desses dias efetivamente houve pluviosidade e o quanto não houve.

Dessa forma, embora se relacione, comumente, a água dos balneários rurais à uma limpidez estática, isto é, ao permanente estado de "água limpa", sabe-se que existe, na realidade, uma rarefação dinâmica da qualidade dessas águas. Esse dinamismo, o qual dividese em sazonal, diário, instantâneo, possui, para bactérias provindas do sistema digestório de animais de sangue quente, correlação com o índice pluviométrico. Assim, torna-se necessária a conscientização dos frequentadores desses locais, bem como a utilização de um marcador fecal mais preciso para análise, como o vírus, justamente para indicar a fonte dessa poluição e delinear, consequentemente, uma ação de quem gere tais balneários para melhorar a qualidade da água.

\section{REFERÊNCIAS}

KLEINHEINZ, G. T.; MCDERMOTT, C. M.; HUGHES, S.; BROWN, A. Effects of rainfall on E. coli concentrations at Door County, Wisconsin Beaches. International Journal of Microbioology, v. 2009, 2009.

RESOLUÇÃO CONAMA no 274, de 29 de novembro de 2000. Disponível em: http://www.mma.gov.br/port/conama/legiabre.cfm?codlegi=272\&gt; Acesso em: 20 mar. 2019.

SHOLTEN, C. Dinâmica temporal da poluição fecal nas águas do córrego rico, manancial de abastecimento da cidade de Jaboticabal - SP. Dissertação (Mestrado em Medicina Veterinária) - Faculdade de Ciências Agrárias e Veterinárias, Unesp. São Paulo, p. 25-38, 2009.

WEATHER UNDERGROUND, estação meteorológica para índice pluviométrico. Disponível em: https://www.wunderground.com/personal-weather-station/dashboard?ID=ITAQUARA3; Acesso em 20 mar. 2019.

VALIAS, A. P. G. S.; ROQUETO, M. A.; CARVALHO A. F.; VULPINI, C. M.; THOMÉ, H. E.; LEME, L. O.; FILHO, L. O. L.; SILVA, M. A. M. L. A água que consumimos município: Aguaí - SP. XII Congresso de Águas Subterrâneas, 2002. 